While the principles of freedom of choice are important, the current trend of increasing motorcycle accidents must be diminished.

T ANDREW

D MILNE

Regional Cardiothoracic Centre,

Freeman Hospital,

Newcastle upon Tyne NE7 7DN

${ }_{1}$ Andrew, $\mathrm{T}$, and Milne, D, Injury. In press.

Department of Transport, Road Accidents Statistics,

3 Bieber, R, Californian Highway Patrol Report, 1977.

\section{Severe hyponatraemia in hospital inpatients}

SIR,-Drs S J Iqbal and P J Ojwang (3 March, p 618) continue to take us to task for having put diuretic-induced hyponatraemia under a "depletional" heading.

We can only reiterate that we ourselves pointed out uncertainties about the pathogenesis of diuretic-induced hyponatraemia in our original paper (4 November 1978, p 1251). As we found that no urinary biochemical measurements distinguish groups of patients otherwise easily distinguished on clinical and radiological grounds, we would prefer to rely on the latter in an emergency. Hence, although we do not feel that our "objectives about patient management" are really different from those of Drs Iqbal and Ojwang, we must beg leave to differ on how to achieve them.

P G KENNEDY

D M MiTCHELL

B I HOFFBRAND

Whittington Hospital,
London N19

\section{Brain failure in private and public life}

SIR,-Dr William Gooddy's lecture on brain failure in private and public life $(3 \mathrm{March}$, p 591) will be of great interest to those who, like myself, are approaching completion of the average life span. Few will quarrel with his main theses-that brain failure is common and has many causes and is (for those escaping other causes of death) ultimately inevitable, that it is more dangerous to the community when it occurs in an influential person, and that it should be prevented if possible. But his list of symptoms and signs of brain failure calls for comment.

Such symptoms and signs may indeed be indicators of commencing brain failure, but surely many of them are no more than evidences of temporary inefficiency of brain function. Incompetence over familiar tasks, for instance, and transient loss of concentration are common enough at all ages, and surely may be no more than signs of fatigue-due, for example, to lack of sleep, a prolonged spell of enforced concentration, or anxiety from some unrelated cause. I am sure that I cannot be alone in having frequently experienced some symptom or sign such as Dr Gooddy has instanced and inwardly lamented, "I am growing old" - only to recall with a relieved start that I had just that symptom as a child or as a student. I think that the point is worth making, because if we accepted Dr Gooddy's list as indicative of brain failure I suspect that we would most of us sink into a state of apprehension and depression, which would perhaps be conducive to accelerated brain failure. Granted that Dr Gooddy referred to his signs and symptoms as "intermittent," saying that the more frequently they occur the more one must be concerned about them; but my own advice to anybody feeling such concern would be to try the effect of a holiday.

Dr Gooddy suggests compulsory retiremen for politicians and other leaders and decision makers at an earlier rather than a later age to prevent the serious consequences of their brain failure. I think I would rather see a system that debars the elderly in influential positions from decision making while retaining them in an advisory capacity so that their experience can be utilised.

LIONEL BACON

Winchester, Hants

SIR,-Dr W Gooddy in his article (3 March, p 591) fails to make it clear what he means by brain failure. The term was originally taken to mean, and is still used to describe, syndromes characterised by impaired social functioning due to an inability to learn, because of a decline of intellect associated with impaired memory. This clinical picture is seen in both acute and chronic organic psychiatric syndromes, but not in neurosis, depression, psychopathy, or functional psychosis, all of which have different treatments and prognoses. Dr Gooddy, however, seems to indicate that he considers them to be causes of brain failure.

$\mathrm{He}$ also states that normal aging ultimately gives rise to brain failure. Society is protected for the most part from people becoming incompetent owing to the failure of the aging brain by compulsory retirement. Compulsory retirement at a fixed age is a crude way of assessing whether a person is fitted to a particular post and is very unfair on the individual whose mental ability is quite adequate, despite his age. Dr Gooddy complains that people in public life often escape compulsory retirement and that society should be protected from their failing brains, and, to such ends, he advocates investigating the brains of the members of the House of Commons and others, using computerised axial tomography. Unfortunately, he does not say to what degree changes shown by such a scan would reflect an impairment of mental ability. If this knowledge is not forthcoming, this method could prove as arbitrary and unfair as compulsory retirement at a fixed age.

Society can probably best guard against unsuitable and incompetent people holding public office, not by invoking medical investigations and opinions, which would be unacceptable to many people, but by devising rules such that people could be easily relieved of public posts if found wanting by their peers.

\section{A J Williams}

\section{Leicester General Hospital}

Leicester LE5 4PW

\section{Whooping-cough vaccination}

SIR,-I feel I must take issue with Dr Alastair G Ironside (3 March, p 619), whose argument seems to be that in whooping cough herd immunity is irrelevant to the vulnerable prevaccination babies and that prophylactic erythromycin for two weeks is a practical alternative.

He bases his opinion on an unspecified comparison of infant mortality between two "outbreaks," one in a "well-vaccinated" population and the other in an "unvaccinated" one. I feel that this is such an important argument that such opinions must be backed by facts and figures or at least a reference. Those of us, as GPs left with the task of advising our new parents about the best course to take, need to be very sure of our facts. This is an area where "maybe" won't do and I feel it is quite wrong to ask the parents to decide unless they too are in full possession of the facts. So perhaps Dr Ironside would support his opinion, and I for one will revise my policy if he can.

Treating at-risk contacts with erythromycin may well be feasible for a physician's child but how does $\mathrm{Dr}$ Ironside think we can get our parents to treat a well child for two weeks with an antibiotic customarily given six-hourly, when it is widely accepted in general practice that it is difficult enough to get them to complete a five-day course for an ill child? Surely, inefficient as it is, a vaccination programme is more likely to succeed-given that we can prove that vaccination protects more than injures and then present the case simply and with one voice to the public.

DAvid TURNeR

Brigstock, Northants

SIR,-Dr A G Ironside (3 March, p 619), while acknowledging that there are no controlled trials available, recommends the use of erythromycin for preventing whooping cough in young household contacts of cases.

Your readers may be interested to know that my college is currently undertaking a controlled, double-blind trial of this procedure. The study is being conducted by the college's Epidemic Observation Unit, which is based in the University of Surrey and is financed by the Medical Research Council.

CLIFFORD R KAY
Chairman,
Research Division

\section{Difficulties in diagnosing meningococcal} meningitis

SIR,-It is surprising that in their short report "Difficulties in diagnosing meningococcal meningitis in children" Drs Oliver R C Smales and Nicholas Rutter (3 March, p 588) do not refer to immunological methods of establishing the diagnosis of meningococcal infection. It is known that countercurrent immunoelectrophoresis (CIE) on cerebrospinal fluid (CSF) is superior to Gram staining in establishing the diagnosis of meningococcal infection and has the advantages that it is $(a)$ rapid, (b) simple, (c) less affected by prior antibiotic therapy, and it enables the organism to be grouped. ${ }^{1}$

Used in conjunction with Gram staining and culture the method increases the number of positive diagnoses made. Moreover, antigen can be detected more often in serum than organisms by blood culture. In particular, in one study of 14 patients with acute meningococcaemia (children with the clinical picture of meningococcal meningococcaemia but with no clinical or laboratory evidence of meningitis) antigen was detected in every patient while blood culture was positive in six out of 11 patients tested. ${ }^{2}$

Finally, patients with group A meningococcal meningitis in whom antigen was detected in blood had a worse prognosis and higher 
incidence of allergic complications than those with no detected antigen in blood. ${ }^{3}$ Furthermore, high concentrations of antigen in CSF at diagnosis with slow disappearance of antigen were associated with neurological damage. Thus, while I agree with the authors' two conclusions, which, I respectfully submit, are self-evident, there are well-known immunological techniques which can improve diagnostic accuracy and which also have some prognostic and epidemiological value.

\section{G Evans-Jones}

\section{Department of Paediatrics, \\ Chester City Hospital}

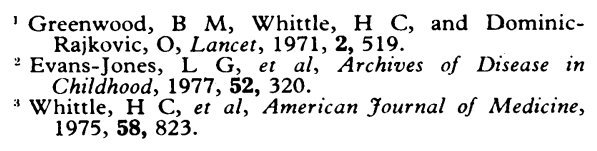

SIR,-Drs Oliver Smales and Nicholas Rutter (3 March, p 588) have once again drawn attention to the difficulties in diagnosing meningococcal meningitis, particularly in an early infection or when antibiotics have been used.

The detection of meningococcal, pneumococcal, and haemophilus antigen by countercurrent immunoelectrophoresis is a wellestablished diagnostic procedure, as efficient as Gram stain and culture combined, and cheap and easy to perform; and it gives an answer in 45 minutes. ${ }^{12}$ The technique is particularly valuable when antibiotics have already been given. It would have been interesting to know how the technique would have fared in the early cases that posed a diagnostic problem for $\mathrm{Dr}$ Smales and $\mathrm{Dr}$ Rutter.

ANTHONY BRYCESON

Hospital for Tropical Diseases,

London NW1 OPE

Greenwood, B M, Whittle, H C, Dominic-Rajkovic, O, Lancet, 1971, 2, 519.

hittle, $\mathrm{H}$ C, et al, American fournal of Medicine,

SIR,-I am glad that Dr O R C Smales and Dr N Rutter (3 March, p 588) have called attention to the importance of a second lumbar puncture when the initial result is unexpectedly normal in patients clinically suspected of having meningitis. I have several times found a second sample taken within two or three hours to be grossly abnormal, perhaps because of layering in the spinal canal. If meningitis is strongly suspected clinically, it may be well worth while obtaining another specimen as soon as the normal report is received.

T H Hughes-Davies

Central Hospital,
Honiara, Solomon Islands

\section{Epilepsy and learning}

SIR,-Your leading article on epilepsy and learning ( 3 March, p 576) suggests that school medical officers should have an opportunity to hear about pupils' learning problems from school teachers. This comes about only if the child is known to suffer from epilepsy. Parents do not necessarily share this information with the school. The school doctor can also be uninformed because both family doctors and hospital paediatricians increasingly consider medical information confidential.
Dr Dorothy $M$ Sell (10 February, p 416) makes this point about sharing medical information in general about children with special educational needs. Information about an epileptic child with behaviour and learning problems in class is helpful; to know about epileptic children before they start a swimming lesson can be vital.

Incidentally, your reference to school doctors "of the new style" having particular schools is relevant only in the context of the DHSS circular you cite: it is a new style for the DHSS. Before 1974 it was the old style, and in the 14 years preceding $1974 \mathrm{I}$ worked in four different parts of the country and always had my own particular schools. Most likely school doctors have had their own particular schools since 1907 .

C R HAINES

School Health Service

Cambridgeshire Area Health

Authority (Teaching),

\section{Stopping lithium prophylaxis}

SIR,-Dr D G Wilkinson (27 January, p 235) reports withdrawal symptoms in a patien with bipolar manic depressive psychosis who had stopped taking lithium after taking it for six years.

In a controlled study of prophylactic treatment of alcoholism by lithium carbonate 20 patients (11 depressed and nine nondepressed) took lithium for a mean time of 41.0 weeks. Each patient was examined at intervals of six weeks, and the lithium dose was adjusted to give serum concentrations of $0 \cdot 8-1.2 \mathrm{mmol}(\mathrm{mEq}) / 1$. The mean lithium level was 0.86 (SE 0.03 ) $\mathrm{mmol} / 1-0.91$ (SE $0.05) \mathrm{mmol} / \mathrm{l}$ for non-depressed patients and 0.80 (SE 0.03 ) $\mathrm{mmol} / \mathrm{l}$ for depressed patients. The lithium was abruptly withdrawn at the end of the study (mean time 41 weeks) and no withdrawal signs were reported by the patients.

While the withdrawal signs reported by Dr Wilkinson were diagnosed as an acute toxic confusional state, the description of the patient after stopping the lithium would fit the diagnosis of a bipolar manic depressive psychosis in relapse.

JULIUS MERRY

Department of Psychiatry,

Epsom District Hospital,

'Merry, J, et al, Lancet, 1976, 2, 481.

\section{Early evidence of asbestosis}

SIR,-I cannot agree with your expert's reply to the question about guidelines for examining employees of a building firm who handle asbestos (10 February, p 388), where it was stated that "the earliest evidence of asbestosis is seldom radiological." In examining workers one rules out biopsy or necropsy evidence which might show pulmonary fibrosis too slight to affect either radiological, physiological, or clinical findings. It is also assumed that your expert agrees that the presence of asbestos fibres or typical ferruginous bodies (asbestos bodies) in sputum can indicate only asbestos exposure and not asbestos disease.

I have just concluded a search of the literature since 1960 on the subject of early diagnosis of asbestosis. Seven papers which reported the findings of authors with extensive experience of routine examination of asbestos workers $^{1-7}$ concluded that the use of highquality $x$-ray films was the best means of routine surveillance. This can well be supplemented by simple lung volume measurements with a robust instrument such as the vitalograph. Regular comparison with the baselines provided by initial examinations enables each man to be used as his own control for early diagnosis.

W J SMITHER

Cape Group of Industries

London WIY 4AB

1 Pilat, L, et al, La Medicina del Lavoro, 1971, 62, 495 Cassan, G, et al, Archives des Maladies Profession nelles, de Médecine, du Travail et de Sécurité Sociale, 1973, 34, 560

${ }^{3}$ Lewinsohn, H C, Royal Society of Health fournal, 92 2.

Beverley, W H A, Journal of the Society of OccupaWeill, H, et al, Archives of Environmental Health, 1975 30, 88.
Weill, $\mathrm{H}$, et al, Archives of Environmental Health, 1976 , W1, 172.

Smither, W J, in Proceedings of the 3rd International Conference on Pneumoconiosis, ed H A Shapiro, $\mathrm{p} 80$ Cape Town, Oxford University Press, 1970.

${ }_{*}^{*}$ *Our expert writes: "The point I wished to make in my brief answer was that unlike, say, silicosis, in which the earliest non-invasive evidence is usually radiological, one should not rely on radiology alone as a monitoring check for asbestosis. Diagnosis of a condition in which the early radiological changes are slight and sometimes equivocal demands that as many other indices as possible should be looked for. Radiology apart, even with sophisticated lung function facilities I would still attach importance to auscultation of the chest for late inspiratory crackles. Details concerning early diagnosis are well discussed by Parkes. $^{1}$ I, of course, agree with your correspondent about the finding of asbestos fibres or ferruginous bodies in the sputum and, as in my original answer, I strongly endorse the value of pre-exposure baselines for the various tests."-ED, $B M \mathcal{}$.

'Parkes, W R, Occupational Lung Disorders. London, Butterworths, 1974.

\section{Minor hazard of amniocentesis}

SIR,-Your leading article on the hazards of amniocentesis (16 December, $p$ 1661) has prompted us to comment on what we have found to be a minor hazard associated with prenatal diagnosis. All laboratories engaged in chromosomal analysis from amniotic fluid cells have experienced, or at least are aware of, the problem of maternal cell contamination. We have recently experienced a source of "maternal cell contamination" hitherto unreported to the best of our knowledge.

A specimen was received labelled as amniotic fluid for chromosome analysis. A culture was initiated in the usual manner using the cell pellet from the specimen obtained after centrifugation. The cells were observed to be growing a few days after culturing, and had an epithelial-like appearance. This cell type from amniotic fluid usually undergoes senescence in a few weeks, and satisfactory chromosome preparation can be difficult to achieve if not obtained early. ${ }^{1}$ The procedure used here for amniotic cell chromosome analysis is to subculture primary cultures once before harvesting the cells. Our attempt to subculture the cells from this specimen after approximately 10 days in culture was not successful.

Meanwhile, an aliquot of the fluid was sent to another laboratory for $\alpha$-fetoprotein assay, as is the routine practice. This laboratory reported that there was no $\alpha$-fetoprotein in the specimen, and that it 